\section{THE CONTROL OF VENEREAL DISEASES.}

THE DIAGNOSIS OF SYPHILIS: ITS TREATMENT BY NOVAKSENOBENZOL, MERCURY, AND IODIDE OF POIASSIUM. ${ }^{1}$

BY H. W. АввотT, M.R.C.S. ENG., L.R.C.P. LoND., MEDICAL EXAMINER TO THE ROYAI, INSURANCE COMPANY.

Most authorities believe that in all probability the incidence of syphilis will be much greater during the immediate future than it has been for many years past. The first line of resistance to this disease will, of course, be offered by the general practitioner, for it will be to him that the sufferer, in the great majority of cases, will apply for treatment. It is therefore a part of the duty of everyone engaged in general practice to become proficient in the newer, as well as in. the older, methods employed for the recognition of specific disease-more especially so because at least one of these more recent methods enables a diagnosis to be made at an earlier stage of the malady than was possible previous to its introduction.

This article is therefore addressea chiefly to the general practitioner, and particularly to the doctor who, living some distance from any of the large hospitals, has not had the opportunity of attending the courses of lectures on venereal disease now so frequently given at these institutions, nor has been able to see the work done at the venereal clinics which have recently been established in various parts of the country. If it leads to an earlier diagnosis in recent cases of syphilis, if it awakens a more lively interest in the newer methods employed for the detection of this disease, its purpose will have been accomplished.

\section{The Value of Early Diagrosis.}

The necessity for an early diagnosis is very urgent, because, by placing the patient under appropriate treatment, his infectiveness is cut short-a most desirable end from the social point of view. It has likewise been found at the Military Hospital, Rochester-row, London, S.W., that only one-half as much treatment is required to clearup a primary case as is necessary for a secondary one.

By the term primary is meant an infection so recent that the blood still gives a negative reaction to the Wassermann test; while by a secondary case is meant a patient who though suffering from comparatively recently acquired syphilis, yet has had the disease long enough for the blood serum to give a positive Wassermann reaction. Most important of all, however, is the fact that it is in these earlier cases that one has the greatest opportunity actually of sterilising the patient-of really and truly curing him. The following is an instance illustrating this:-

M. - - presented himself on Jan. 23rd last complaining of a penile sore and giving the history that the lesion had commenced ten days previously with the formation of a papule, which had gradually developed into the ulcer for which he now sought treatment. The chancre was about one-half of an inch in diameter and was fairly typical of specific disease; there was, however, no distinct rash, but the patient had characteristically enlarged inguinal glands. Two capillary tubes were charged with the serum expressed from the sore, one of which was sent to the Great Northern Hospital, Holloway-road, N., for examination, the contents of the other being examined by myself the next day. Spirochatce pallide were isolated in both specimens and the patient was given $0.45 \mathrm{~g}$. of novarsenobillon by intravenous injection in the afternoon of the day following that on which he had first presented himself. In all ten injections were given, of varying doses of novarsenobillon, the maximum amount reached being $0.9 \mathrm{~g}$. The intravenous medication was combined with weekly intramuscular injections of $1 \mathrm{gr}$. of mercury. At the end of the course-that is, in April-a specimen of blood was sent to the pathologist at Charing Cross Hospital, and a report was received that the blood serum gave a negative reaction to the Wassermann test. A second specimen was sent in July, and a third in November with a similar result. No rash developed; there has been no throat lesion, no iritis, no periostitis, no alopecia, no secondary symptom of any kind other than the glands; in fact, the patient has never suffered from any obvious manifestations of syphilis beyond the initial penile

1 A paper by Mr. H. W. Abbott on Sisme Practical Points in Intravenous Medication, appeared in THx LANCEr, Oet. 20th, 1917 (p. 616) sore, which healed a few days after treatment was commenced, and the enlarged glands, which soon disappeared.

I am of opinion that, owing to the early vigorous treatment he received, this patient's blood serum never did become positive to the complement reaction, and that in all probability he has really been cured. Moreover, this case is not an isolated one, but is quite typical of what can ordinarily be accomplished by making an early diagnosis and by beginning treatment without any delay. The importance of early treatment has been emphasised by Colonel F. W. Mott in the following note, which has been written with special reference to this paper:-

"After the organism has been disseminated throughout the body, including the nervous system, treatment becomes much more difficult to be successful in fact, it is doubtful when once the spirochæte has gained access to the cerebrospinal fluid it can ever be eradicated. Certainly the existence of the spirochrete in the central nervous system produces a positive complement reaction of the fluid, and I have not yet seen a positive fluid become negative by treatment, although a coincident lymphocytosis may disappear with treatment."

\section{Methods of Diagnosis.}

The means of detecting syphilis can perhaps best be enumerated under the following four heads:-

1. The physical examination of the patient.

2. The microscopical examination of the serum obtained from a penile sore or from some other lesion.

3. The examination of the patient's blood serum, for the complement-fixation reaction (the Wassermann test)

4. The examination of the cerebro-spinal fluid.

\section{I. - The Physical Examination of the Patient.}

The physical examination of the patient is, of course, the method which has been practised from the early ages for the detection of specific disease, and although the importance of the other three more recent means of diagnosis can scarcely be over-stated, yet the physical examination of the patient still remains a most important part of the ordinary routine method of investigating cases of suspicious venereal disease. A description in detail of the physical examination of a patient suspected to be suffering from specific disease would however, occupy too much space to be included in the present paper ; moreover, the reader can consult any good text-book on the subject.

1I.-The Mioroscopical Examination of the Serum Obtained from a Syphititic Sore.

This method of diagnosis is within the competence of any practitioner; it can be completed in a few moments ; it gives a diagnosis which is quite unequivocal-absolute-final. If Spiroohate pallida be found under the microscope in the serum obtained from a suspicious lesion in one of our patients, then that patient is suffering from syphilis. It must be borne in mind, however, that in all probability spirochætæ will not be obtainable from a syphilitic sore to which antiseptics have recently been applied. The surface spirochætæ will certainly have been killed by such procedure; so that if a patient presents himself with a penile sore, which, as is frequently the case, he has himself been treating with some form of antiseptics, it is best to send him away for 24 hours, with instructions freely to wash the sore during the interval with saline or plain boiled water. On his return a specimen of serum can be obtained which will show spirochætæ if the patient be suffering from specific disease.

The method of procedure adopted in order to procure such a specimen is much the same for all lesions, but a penile ulcer will be taken as typical.

A syphilitic sore may be said to consist of two parts : 1. An ulcerated centre (Fig. 1, A.) 2. The more or less clean erge around this central ulceration (B), surrounded by an indurated margin (C).

The area richest in spirochætes is the rim of tissue just within the normally indurated margin-that is, the more or less clean edge which encloses the ulcerated centre.

FIG. 1.

It is not very likely that you will obtain spirochætes from the ulcerated surface in the centre of the chancre, because 
the Spirochata pallida is truly parasitic-it subsists on living tissue; it is not a saprophyte-it does not thrive on dead matter. So it will be wise to obtain the specimen from the area just within the hard margin surrounding the sore. First protect the hands with rubber gloves, and place a bowl of 1-1000 perchloride of mercury solution in a handy position. Next take a swab of lint soaked in sterile water or saline, and cleanse the sore so as to get rid of surface débris, \&c. Then dry it. Our object now is to excite the flow of secretion from the ulcer, because the serum in exuding carries with it the Spirooheta pallida. In order to promote this secretion of serum, several methods have been advocated by different workers, viz. :-

1. Take a dry swab and rub the surface of the ulcer fairly hard.

2. Dab the sore several times with lint or wool soaked in spirit; after a minute or two dry the surface, rubbing moderately hard.

3. Immerse a swab in water or saline as hot as can be borne, wring fairly dry, and apply the hot swab to the sore.

4. Take any instrument with a blunt edge- - s spud will do very well, or the back of a scalpel-and gently scrape the edge of the sore so as to push the epithelium towards the bealthy skin. This manipulation bares the surface without producing much, if any, hæmorrhage.

The final manoeuvre in all these methods is to squeeze the sore hard, which is somewhat painful, but is only of momentary duration, and patients do not as a rule complain mucb. You will by this means express a quantity of secretion with little or no blood.

Now we have the penile sore plentifully bathed with serum. To collect this, take a glass capillary tube, similar to that in which ordinary calf lymph is frequently supplied, and prepare it beforehand thus :-

Break off both ends by gently filing and snapping across at the file mark. Put the extremities into the flame of a spirit lamp for a second just to smooth each broken end, which does not then feel sharp to the patient when it is used. Now apply one end to the expressed exudate. Hold the tube nearly horizontal, the serum will run in more freely than if you hold it vertically - gravity will not then be opposed to capillary attraction. Place the end into the exudate only sufficiently far that it be just covered, and as soon as you have exhausted the exulate in one spot go to another, and so coax the secretion into your capillary tube. Usually several tubes can be charged from the serum thus expressed from the chancre; two or three are sufficient. Some authorities advocate the addition of a drop or two of distilled water or normal saline to the exudate before its collection into the capillary tube, on the ground that it renders the serum more attenuated and thus facilitates its collection. For this purpose the serum from the penile sore is first transferred to a microscopic slide and diluted there with the normal saline before being drawn into the capillary tube. The spud or scalpel used for scraping the ulcer can be employed to convey the exudation from the chancre to the slide. You will, however, find that this addition is not necessary if you squeeze the sore really hard. Thousands of specimens have been successfully collected at the Military Hospital, Rochester Row, by following the technique described under headings 3 and 4 -the application of a heated swab being the favourite method. Indeed, if pressed for time, sufficient exudation can nearly always be obtained simply by squeezing the sore hard after it has been freed from débris.

When the exudate has been collected gently shake it into the middle of the capillary tube by a movement somewhat similar to that employed in resetting a clinical thermometer. Then seal both ends by means of a spirit lamp. The exudate will show the $S p$. pallide for three weeks.

To obtain specimens from ather lesions. - It is rare to fail to find spirochretes in the serum expressed from such lesions as the condylomata, frequently found between the buttocks, moist papules on the scrotum, syphilitic papules on the skin, mucous tubercles on the inside of the mouth, ulcers on tonsils, fauces, \&c. In fact, papules no larger than a pin's head have yielded sp. pallida. If necessary gently remove the superficial epithelial cells until a raw surface appears, then proceed as you would for the expression of serum from a penile sore. In the case of syphilitic papules on the skin, one can promote a secretion of exudate by a method which was first described by Lieutenant-Colonel I. W. Harrison :-

Remove the superficial layer of cells; heat the bottom of a test tube, smear the open end with vaseline, and apply it as a suction cup. Collect, in a capillary tube as before described, the serum which will be found bathing and swelling the papule. Mucous patches in the month are very prolific sources of $S p$. pallida. Instruct the patient to turn his lips or cheeks outwards. The surgeon dries the surface, keeping it free from saliva, and collects the exudate as usual.

Another method of obtaining material for the microscopical search for $S p$. pallide is by gland puncture. This is very useful in cases where the patient presents himself with the sore healed, or plastered over with antiseptics, and with no other syphilitic lesion from which serum can be expressed. The technique is as follows :-

Manipulate the gland with your left hand until it is tightly presenting under the skin. This is easy to do, because the gland is painless. Take a hypodermic syringe, with an intramuscular needle, which is stouter than that ordinarily supplied with the instrument. Pass the needle from above downwards into the midale of the gland, following the oblique line of the groin. You can tell when the needle point is in the gland, because on bodily moving the needle, you will find that you are also bodily moving the gland. In applying this test you must, of course, loosen the hold of your left band upon the gland. Now force about 10 minims of normal saline through the needle into the tissue surround ing its point--that is, into the centre of the gland, so as to create a space at this spot. Without removing the needle massage the gland in order to make a mush of tissue and water. Then withdraw the material so obtained, and yon have a fluid in which, although blood-stained, Sp. pallidie are very frequently to be found.

The above technique was first described by $\mathrm{Mr}$. C. $\mathrm{H}$. Mills, of the Military Hospital, Rochester Row.

To get the specimen out of the tube take a piece of blotting-paper, fold it and break the tube at one end nside the blotting-paper. If you do not use this protection spiculæ of infected glass may lodge on the skin of the fingers. Hold a microscopic slide in readiness in the left hand, and having gently grasped the tube with light spring forceps, apply the sealed end to the flame of a spirit lamp or a Bunsen burner. The heat, by expanding the air in the tube, expels the exudate on to the slide held in the other hand. Should there be any bubbles in the serum after its expulsion on to the slide, heat the end of the capillary tube and touch each bubble with it, they will disappear. If you consider you have not sufficient exudate add a drop of normal saline or distilled water by dipping a spud, previously sterilised in the flame, in this liquid and mix it with the exudate.

Now place the cover-glass on the specimen, preventing as far as possible, the formation of air-bubbles. It is best done thus: Hold the cover-clip with suitable forceps, Cornet's or Blackley's slide-holding forceps answer very well, and allow one end of the cover-glass to touch the microscopic slide first. Then gently lower the other end until it is horizontal (see Fig, 2, a. b. c.).

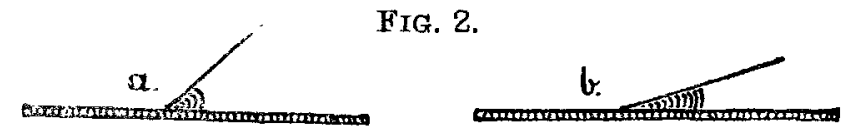

\section{c.}

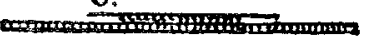

Showing the method of lowering the cover-glass on to the slide, between.

It is much easier to prevent the formation of air-bubbles in the exudate if there be a good-sized drop on the microscopic slide when you let the cover-glass down. This is one of the reasons for the addition of the normal saline. It increases the bulk of the specimen.

Lastly, lay the slide on a flat surface and cover it with a piece of blotting-paper. Press hard, as you would drying a letter. The blotting-paper absorbs any excess of exudate and spreads it thinly and evenly under the cover-glass.

The Actual Microsoopical Examination for the Deteotion of Spirochætæ Pallidæ.

The microscope should be fitted with a mechanical stage provided with rectangular movements. It must also have a dark-ground condenser, and many workers prefer a hemispherical condenser to a paraboloid - the former gives keener definition. Swift's hemispherical dark-ground condenser is a very good one. So is Baker's. Leitz's is perbaps the best of all. For illuminating the dark ground Clarke's sub-stage illuminator is quite satisfactory. It works with a 4-volt accamulator, the light is sufficient; moreover, being portable, it can be used anywhere. The bulb is adjustable, and in practice is placed under the condenser. The apparatus is made by Messrs. Hearson and Co., 235, Regentstreet, London, W., and the cost is quite moderate. O course, however, any practitioner who has an installation of 
electric light can, if preferred, readily obtain a miniature arc lamp or a Nernst light. Of arc lamps that known as Mills's lamp, and made by Messrs. Wrench and Son, Gray's Inn-road, is a particularly suitable light for the examina. tion of the $S p$. pallide by the dark-ground illumination, but a Nernst lamp, of the pattern made by Leitz, is perhaps more convenient. The light from incandescent gas, properly shaded, can also be used.

The slide having thus been made ready for the examination, the observer should go to the microscope and so adjust the source of light and the mirror that good illumination is obtained, after which the first thing to do is to centre the dark-ground condenser. To do this, bring its surface into sharp definition by use of the lower power objective, say $2 / 3$ inch, and there will be noticed two or three concentric circles marked thereon. Centre these rings in the field of view by means of the screws provided. Next-

1. Rack the condenser down out of the way.

2. Put a large drop of cedar-wood oil on the under-surface of the slide, turn it quickly over to prevent the oil from spreading, and place the slide in position on the mechanical stage.

3. Raise the dark-ground condenser up to the slide until it is actually in contact with it.

4. Still using the low-power objective, bring the specimen into definition, and you will notice in the dark ground a patch of light, which is the focus, more or less sharp, of the condenser. Manipulate the mirror until the light occupies the centre of the field, and then rack the condenser into such a position that the bright area becomes as well defined and brilliant as possible. Then you will have brought the rays from the dark-ground condenser to a sharp focus within the film of exudate.

5. Put a small drop of oil on the surface of the cover-glass and change the $2 / 3$ inch objective for the $1 / 12$ inch oiladjustment until it is very lightly touching the cover-glass.

6 . Readjust the mirror if necessary so as to obtain good illumination.

We have, of course, placed the $1 / 12$ inch objective too low for it is touching the cover-glass. Hence very slowly and carefully raise it until something comes into view. This will most probably be the film of exudate, and it will look like a darkened background in which are seen numerous light spots. Focus this, with the fine adjustment as sharply as is possible. Before critical definition is obtained, however, a little further manipulation of the condenser, mirror, and objective may be found necessary; but by careful adjustment of these three factors you will observe that the specimen becomes keenly defined when a darkbluish-grey coloured field will be seen, in which are numerous bright, well-defined particles (spores, débris, \&c.) These you will notice exhibit Brownian movement, and often travel across the field of view pretty rapidly owing to currents in the film set up by movement. If, however, the specimen is in a state of rest the field of vision, when critically defined, often reminds the writer of the appearance of the starry heavens, the Brownian movement of the microscopic particles being the counterpart of the twinkling of the stars.

You will now know that you have under accurate observation the layer of exudate. You should be able to locate the specimen before the lens has been raised very far. If you have not succeeded in so doing by the time that it has travelled upwards so high that the lens has almost separated from the oil, then you certainly have missed the film, very probably having gone through it so rapidly as not to notice its presence.

If this has happened, very slowly and attentively lower the objective, and you will probably catch a glimpse of the exudate as you move the lens down. If not, continue until the lens is lightly resting on the cover-glass again, and start afresh.

Should the microscopic slide selected be exactly the correct thickness for the condenser you are using (i.e., $1 \mathrm{~mm}$. for the paraboloid, $1.1 \mathrm{~mm}$. for the hemispherical) there will be little or no need for altering its position, and such a slide should alwavs be used. If one which is too thick be employed, the rays of light will be brought to a focus within the glass of the microscopic slide-i.e., below the specimenand the definition will not be so good as if a thinner one had been selected.

On the other hand, if one uses a slide much too thin, although compensation can be made by lowering the condenser, yet by so doing the circumference of the drop of oil becomes progressively smaller as it is drawn between the separating surfaces of the slide and condenser, and the observer is then apt to get reflection from the edge of this lessened circumference.

Beware of air-bubbles in the cedar-wood oil which you put on the slide. These are of ten fatal to a satisfactory examination as they diffract the light so much that everything becomes fuzzy. If this should occur, remove the offending material, polish the condenser, and apply fresh oll, more carefully this time!

We have now to search the field for $s p$. pallida. It is best to work systematically. Start from one end of the specimen, and, by means of the screw provided for the purpose, move the slide laterally along through its entire course to the other end. At the same time continuously raise and lower the objective, by means of the fine adjustment, so that the whole depth of the film comes alternately in focus, thus searching the exudate from the top to the bottom as it is travelling along. When you have arrived at the end of the traverse move the slide a short distance at right angles to the direction of the first movement so as to get anotber portion of the film into view, and continue to work back again, and so on. You will not have continued your examination long before you will be rewarded by seeing one or more silvery-looking spirals appear within the field of observation. Focus one carefully and watch it, keeping the organism always in the centre of the field by altering, as necessary, the position of the slide. If the exudate be examined within a few hours of its collection the Sp. pallida will be alive, and you will observe some or all of the following movements :-

1. Bending, which is the most marked.

2. Snake-like undulations.

3. Wriggling movements a twisting of the body to and ro in short curves, like an eel.

4. Occasionally a local wave of contraction may be seen which flattens out some of the spirals.

5 . Concertina-like movements by which the spirals are drawn out or approximated, so that the organism becomes lengthened or shortened respectively.

6. Rotation round its long axis like a screw.

Notwithstanding that $S p$. pallida possess rapid local movements, yet they do not travel across the field of view at all quickly; indeed, the parasite often remains in practically the same position for a considerable time. The writer has watched the movements of a $S p$. pallida for half an hour without having to alter the position of the microscopic slide. This slow locomotion serves to distinguish it from Sp. gracilis and $S p$. refringens, the only other two spirochætes at all likely to be encountered while searching for $S p$. pallida from lesions other than those in the mouth.

$S p$. gracilis is coarser and moves fairly fast, while Sp. refringens is much longer and thicker and travels with far greater rapidity.

Although Dr. Mott has succeeded, by taking special precautions, in keeping the $S p$. paltida alive for 18 hours. yet if the examination be postponed for more than five or six hours the organisms under ordinary conditions will probabl be dead. You will then see the spirals, but there will not be any movement other than Brownian motion; and you will notice the spirals number usually about a dozen. If, however, for any reason the actual examination fo: the detection of the $S p$. pallidac be not undertaken by the doctor, then the capillary tube or tubes containing the exudate should be sent carefully packed with wool, in a wooden or metal box, to a pathologist. These outfits for the collection and transmission of specimens can be obtained from any hospital connected with the V.D.A. scheme, or from any pathological institution-e.g., the Clinical Research Association, Watergate House, Adelphi, London, W.C. ; the Lister Institute of Preventive Medicine, Chelsea Bridgeroad, London, S.W.; the Virol Research Laboratories, 10, Bedford-square, London, W.C.

Do not be misled by a single failure to find the Sp. pallida into the belief that the patient is free from syphilis, for he may have been exposed to pyogenic organisms, as well as to syphilis. The former element becomes manifest a few days after infection, but the latter may not become apparent until after the lapse of several weeks.

The soft chancre argues a breach of surface at the time of exposure; the all-important thing to determine is whether this solution of surface has been infected with $s p$. pallide. Hence, if a patient appear with a penile abrasion of any description keep him under observation for two months, taking a number of microscopical specimens and testing the blood during the period of observation.

In connexion with this point Professor Mott has added the following note :-

"No venereal ulcer should be regarded as a soft sore until it has been definitely proved, by repeated examinations, that the syphilitic organisms are absent and that subsequently, when sufficient time has elapsed, the blood is found to give a negative complement reaction. I consider this by far the most im portant statement that can be made, for a large pro- 
portion of the cases of tabes and general paralysis are due to undiagnosed syphilis, the so-called soft sores often being really of syphilitic origin."

The one great thing in these early cases is to be able to obtain a rapid diagnosis; and if the general practitioner has neither the time nor the inclination to undertake the microscopical extmination himself, then the essential thing required from him, unless he can send the patient to a venereal clinic or a hospital, is to obtain the material for this purpose, and send it to a pathologist. The collection of this exudation is as easy to undertake as it is to obtain a specimen of blood for the Widal test in cases of suspected typhoid fever. (To be conciuded.)

\section{PARIS.}

\section{(FROM OUR OWN CORRESPONDENT.)}

\section{Increase in Seabies.}

THE war has increased the frequency of scabies. Although exact figures are lacking it is a matter of common knowledge that a large number of soldiers suffer from itch. Three special hospitals are reserved in Paris for the treatment of itch : the St. Lonis, the Broca, and (since April, 1915) the Cochin ; and M. Thibierge's recent report to the Academy of Medicine covers the observations made at them. During mobilisation the number of cases treated sank abruptly as a result of the exodus from Paris of a large proportion of the workers. Among women the figures have varied little, so that, making due allowance for the increase in the female population, calculation of the actual increase in frequency is a simple matter. In comparison with the year 1914 this increase amounts to 350 per cent., distributed among all classes of the population. Among civilians in his own out-patient practice Dr. Thibierge notes an increase in the proportion of cases of itch from 1 to 12 per cent. $\mathrm{He}$ accounts for the increase by the present difficulties in connexion with laundry work and the disinfection of blankets and sleeping sacks, possibly also by the contamination of the straw used for the bedding of the soldiers. Among the civi population the increase is attributed largely to infection from soldiers home on leave. Women often develop the condition a few days after the arrival of their husbands on leave. Presumably there is the same risk from the bed linen in the humbler hotels where soldiers pass an occasional night and from the clothing which they put out to be mended. M. Thibierge thinks that some of the less common signs of scabies are not familiar to all doctors, and therefore at times the condition escapes prompt treatment.

\section{Poison Gas and Tuberoulosis.}

Dr. Marcel Pinard, Médecin-Major of the second class, has made some interesting observations on the effect of the toxic gases employed by the Germans. Certain soldiers after exposure to poison gas have 12 or 15 days later developed severe nettle rash accompanied by cedema, and have later shown signs of tuberculosis at the pulmonary apices. Poison gas is, he thinks, capable of producing rapid development of a focus of latent tuberculosis which might otherwise have remained dormant. This question deserves study in regard to the responsibility of the State in pensioning the victims of poison gas, and accentuates the importance of acute nettle rash, demonstrated as a sign of reaction to tubercle toxin in certain subjects, a peculiarity to which Landouzy first drew attention.

Reuben Harvey Memoriat Prize.-This prize which is open to all students of the various schools of medicine in Dublin which are recognised by the medical licensing bodies in Ireland and also to graduates or licentiates of these bodies of not more than three years' standing at the time of the award, is given triennially, and the twelfth award will be made on July 1st, 1918. The prize, value $£ 25$, will be awarded to the writer of the best essay, on a subject to be selected by the candidate, evidencing original research in animal physiology or pathology. Furtber particulars may be obtained from Dr. T. Percy C. Kirkpatrick, Fellow and Registrar, R.C.P.I.; Dr. C. M. Benson, Fellow and Socretary to the Council, R.C.S.I.

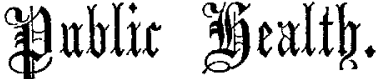

\section{ANNUAL REPORTS OF MEDICAL OFFICERS OF HEALTH.}

County Borongh of St. Helens.-Dr. Joseph Cates's annual report for 1916 contains much interesting matter which bears testimony to the good work being done under his direction by the health department of St. Helens. The scheme for the prevention of infant mortality continues to be vigorously prosecuted. The attendance at the maternity centre held in the medical officer's department at the town hall has proved so successful that a second centre is being established in the Marshalls Cross district, and it is hoped that a third, in conjunction with a day nursery, will shortly be opened in premises in Oxford-street. 850 attendances were made by mothers, 864 by infants to the infant welfare centre, and 17 mothers and 47 children were treated in the corporation hospitals. In connexion with post-natal work the health visitors made 4116 first visits and 9057 total visits to infants and young children. As regards ante-natal work, 553 expectant mothers were visited, and almost without exception the visitors were well received. Four expectant mothers were admitted for treatment into the corporation hospitals. In reviewing the work of the year in this department, however, Dr. Cates emphasises the urgent need of greater expenditure and further effurt if St. Helens is to lose the unenviable position it holds among towns with a high child mortality. A large amount of work arising out of the war has been carried out by the public health officials. A close inspection has been maintained of premises from which food is supplied to the Army, and inquiry has been made into cases of infectious diseases coming into the borough after discharge from military hospitals. Men suspected to be suffering from tuberculosis have been examined at the request of the recruiting officer, and bacteriological examinations have been conducted in the municipal laboratory. Soldiers suffering from infectious or contagious diseases have been admitted into the corporation hospitals, and the disinfection of billets, bedding, and clothing has been carried out. In Dr. Cates's opinion there are five outstanding requirements which should be carried out if the health of the borough is to be improved : (1) The provision of houses for the workingclass and the closing and clearance of certain insanitary areas; (2) the provision of adequate hospital accommodation for maternity and for infectious diseases; $(3)$ the conversion of the pall closets and privies now in use ; (4) the abolition of the bricked ashplaces and the provision of closed ashbins ; (5) the paving of yards. It will doubtless be diffcult or impossible for the borough council to give effect to these recommendations during war-tim, but if plans were prepared now the work could be commenced with as little delay as possible after the termination of hostilities.

County Burough of Portsmouth.-In his annual report for 1916 Dr. A. Mearns Fraser expresses the view that the most important health measure of the year was the provision made by the Portsmouth town council for the diagnosis and treatment of venereal diseases. He states that Portsmouth was the first provincial town in the country to prepare a working scheme for this purpose, and his report on the sunject, dated September, 1916 (which is given in the annual report), is interesting, and may be briefly summarised. The treatment of these diseases will be carried out at the Royal Hospital under the direction of a specially trained medical officer. The clinic will be held on three afternoons and evenings a week, female patients being seen from 330 to 5.0 , and male patients from 60 to 7.30. These times for attendance may be varied and extended as experience proves necessary. Two beds in the hospital will be provided for male and two for female patients. The medical officer and necessary staff will be appointed by the Royal Hospital committee of management, subject to the approval of the Local Government Board. Laboratory facilities in connexion with the treatment and prevention of venereal disease will also be provided at the Royal Hospital. Salvarsan, or its approved substitutes, will be issued to medical practitioners free of charge by the medical officer of the treatment centre or by the medical officer of health. Apparatus for the purpose of collecting material for examination from sus- 